Discussiones Mathematicae

\title{
THE PROPER DIAMETER OF A GRAPH
}

\author{
VinCENT COLL \\ Lehigh University, Department of Mathematics \\ Bethlehem, PA 18015, USA \\ e-mail: vec208@lehigh.edu \\ JONELLE HOOK \\ Mount St. Mary's University \\ Department of Mathematics and Computer Science \\ Emmitsburg, MD 21727, USA \\ e-mail: jhook@msmary.edu \\ Colton Magnant \\ Georgia Southern University \\ Department of Mathematical Sciences \\ Statesboro, GA 30460, USA \\ e-mail: cmagnant@georgiasouthern.edu \\ Karen MCCREAdy \\ King's College \\ Department of Mathematics and Computer Science \\ Wilkes-Barre, PA 18711, USA \\ e-mail: karenmccready@kings.edu \\ AND

\section{KATHLEEN RYAN} \\ DeSales University \\ Department of Mathematics and Computer Science \\ Center Valley, PA 18034, USA \\ e-mail: kathleen.ryan@desales.edu
}




\begin{abstract}
A proper edge-coloring of a graph is a coloring in which adjacent edges receive distinct colors. A path is properly colored if consecutive edges have distinct colors, and an edge-colored graph is properly connected if there exists a properly colored path between every pair of vertices. In such a graph, we introduce the notion of the graph's proper diameter - which is a function of both the graph and the coloring - and define it to be the maximum length of a shortest properly colored path between any two vertices in the graph. We consider various families of graphs to find bounds on the gap between the diameter and possible proper diameters, paying singular attention to 2-colorings.
\end{abstract}

Keywords: diameter, properly connected, proper diameter.

2010 Mathematics Subject Classification: 05C12, 05C15.

\title{
REFERENCES
}

[1] E. Andrews, E. Laforge, C. Lumduanhom and P. Zhang, On proper-path colorings in graphs, J. Combin. Math. Combin. Comput. 97 (2016) 189-207.

[2] V. Borozan, S. Fujita, A. Gerek, C. Magnant, Y. Manoussakis, L. Montero and Zs. Tuza, Proper connection of graphs, Discrete Math. 312 (2012) 2550-2560. doi:10.1016/j.disc.2011.09.003

[3] G. Chartrand, G. L. Johns, A. K. McKeon and P. Zhang, Rainbow connection in graphs, Math. Bohem. 133 (2008) 85-98.

[4] G. Chartrand, G. Johns, K. McKeon and P. Zhang, The rainbow connectivity of a graph, Networks 54 (2009) 75-81. doi:10.1002/net.20296

[5] S. Fujita, A. Gerek and C. Magnant, Proper connection with many colors, J. Comb. 3 (2012) 683-693. doi:10.4310/JOC.2012.v3.n4.a6

[6] E. Laforge, C. Lumduanhom and P. Zhang, Characterizations of graphs having large proper connection numbers, Discuss. Math. Graph Theory 36 (2016) 439-453. doi:10.7151/dmgt.1867

[7] E. Laforge, C. Lumduanhom and P. Zhang, Chromatic-connection in graphs, Congr. Numer. 225 (2015) 37-54.

[8] X. Li and C. Magnant, Properly colored notions of connectivity - a dynamic survey, Theory Appl. Graphs 0 (2015), Iss. 1, Article 2.

doi:10.20429/tag.2015.000102

Received 23 January 2017

Revised 15 February 2018

Accepted 15 February 2018 